\title{
Trajetórias de vidas marcadas pela violência: aspectos macrossociais e subjetivos
}

DOI: https://doi.org/10.5935/1984-9044.20200011

\author{
Vanessa Eda Paz Leite ${ }^{1}$ \& Rosana Teresa Onocko Campos ${ }^{2}$ - Universidade \\ Estadual de Campinas (UNICAMP)
}

Resumo: Este artigo parte da experiência de dois anos em um Programa de Residência em Saúde Mental e Saúde Coletiva e objetiva fazer uma reflexão sobre as diversas formas de violência presentes na vida dos sujeitos com quem tomamos contato. Iniciamos a discussão chamando a atenção para a invisibilidade daquilo que Zizek (2014) nomeia como violência sistêmica. Em um segundo momento, partimos das contribuições da psicanálise para refletir sobre o efeito transgeracional da violência e utilizamos o relato de experiência e o estudo de caso para analisar algumas situações reais. Por fim, chamamos atenção para a importância do ato clínico e político de resgatar a memória e ajudar esses sujeitos a produzir narrativas próprias acerca desses acontecimentos traumáticos.

PALAVRAS-CHAVE: violência; neoliberalismo; relatos de experiência; psicanálise; políticas de saúde.

\section{Lives marked by violence: macrosocial and subjective aspects}

\begin{abstract}
This article, which concerns two years of experience in a Residency Program in Mental Health and Public Health, aims to make a reflection about the many ways in wich violence presents itself in people's life history who were assisted. We started the discussion the invisibility of what Zizek (2014) calls systemic violence. In a second moment, we use the contributions of psychoanalysis to think about the transgenerational effect of violence. We used an experience report and a case study to analyze some real situations. Finally, we emphasize the importance of the clinical and political act of searching the memory and helping these people to produce their own narratives about these traumatic events.
\end{abstract}

KEY WORDS: violence; neoliberalism, experience reports; psychoanalysis; health policies.

1 ORCID: https://orcid.org/0000-0003-1724-7723

2 ORCID: http://orcid.org/0000-0003-0469-5447 


\section{Introdução}

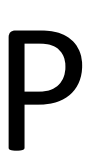

artimos da experiência de dois anos em um programa de residência multiprofissional em saúde mental e saúde coletiva, cujos campos de atuação se deram em instituições de saúde (CAPS i e Centro de Saúde) que atendem diversos segmentos populacionais, dentre eles muitos são pobres, negros e marginalizados. Levando em consideração essa população e à luz daquilo que Coimbra (2001) nomeia como "ideologia das classes perigosas", na qual há uma relação ideológica direta entre pobreza e perigo - considerando que ela traz ameaças, doenças, violência etc. - procuramos, com o presente artigo, propor uma reflexão sobre a atenção dispensada pelo Estado e suas instituições representativas - mais especificamente as da saúde - a esses sujeitos.
O "medo social" da suposta violência atribuída a essa população tem gerado respostas cada vez mais penais, repressivas, violentas e simplificadoras por parte do Estado, como é o caso da criminalização da pobreza. Além disso, temos assistido ao crescimento do aparato repressivo e da discursividade de ódio e extermínio daqueles que são tidos como "perigosos" (Souza, 2005). Partindo desse pano de fundo, temos por objetivo refletir sobre as diversas formas de violência dirigidas a essa população, bem como as manifestações de sofrimento psíquico advindos dessas experiências. A partir dos relatos de experiência também procuraremos apontar ações na área da saúde mental e coletiva que possam produzir reflexão e transformação que auxiliem na diminuição do sofrimento psíquico gerado pelas situações de violência. 


\section{Violência invisível do capitalismo global: aspectos macropolíticos}

\section{O Estado capitalista atua como mediador} e apaziguador de conflitos gerados pela divergência existente entre interesses da burguesia em oposição aos interesses da classe trabalhadora (Hoflin, 2001). É nesse sentido que Lênin (1918/2010) aponta que o Estado é o próprio produto do antagonismo de classes. O neoliberalismo, por sua vez, resulta de uma implementação da política liberal numa conjuntura favorável à aplicação de seus princípios, manifestando-se como reedição do liberalismo (Euzébios Filho, 2016). Assim, vivemos uma conjuntura política que permite ao capital adentrar todas as esferas da vida; no campo das políticas públicas de saúde, isso não é diferente. Tais políticas são investidas cada vez mais pelo capital privado, "permitindo as empresas competirem no mercado de 'responsabilidade social', no eterno retorno do assistencialismo." (Leite e Euzébios Filho, 2018).
Os pressupostos neoliberais têm o Estado mínimo como uma de suas prerrogativas, uma vez que, dentro dessa lógica, as intervenções estatais inibem a iniciativa privada e criam obstáculo para que as pessoas individualmente alcancem o mérito, se apresentando como um empecilho para o desenvolvimento econômico (Hofling, 2001). Assim, podemos dizer que as políticas econômicas e sociais no neoliberalismo contribuem não para uma exclusão propriamente dita, mas para uma inclusão precária e marginal.

Dessa forma, entendemos o fenômeno da inclusão/exclusão a partir da lógica dialética, assim como proposto por Sawaia (2001), que nos aponta que "A sociedade exclui para incluir e esta transmutação é condição da ordem social desigual, o que implica o caráter ilusório da inclusão." (p. 8). O avanço das políticas neoliberais acirra ainda mais os 
discursos de competitividade, lei de mercado, Estado mínimo e necessidade de privatizações que se concretizam nas parcerias público-privadas. Dentro da lógica capitalista, serviços básicos são transformados em mercadoria e àqueles que não estão inseridos como consumidores resta a inclusão por meio da miserabilidade (Coimbra, 2000).

Partindo de uma análise dialética, consideramos também que, apesar de o Estado ter um caráter classista e ser hegemonicamente burguês, ele também é, em sua contradição, poroso à disputa por interesses da classe trabalhadora sendo, portanto, palco da luta de classes, de modo que as políticas públicas de saúde também se encontram inseridas nessa disputa. Assim, temos, por um lado, o dever do Estado na implementação do SUS e a efetivação de seus princípios básicos de universalidade, equidade e integralidade; por outro, encontramos inúmeras dificuldades em seu processo de implementação, como o financiamento insuficiente, atenção primária crescendo em velocidade e qualidade abaixo das necessárias etc. (Campos, 2007).
A partir dessas considerações, podemos dizer que a atual conjuntura pressupõe uma violência fundamental. Zizek (2014) nos chama atenção para a invisibilidade diante dos efeitos nefastos provocados pelo capitalismo global, apontando a violência sistêmica como aquela que sustenta um certo estado das coisas percebido como normal. Há, ainda, segundo a lógica neoliberal, uma desvalorização da noção da política, que se apresenta como ultrapassada, restando ao Estado a administração especializada e eficaz da vida, ancorada em uma perspectiva objetiva e despolitizada. Tal forma de governar, conduzida por expertises da administração, é apontada por Zizek (2014) como um campo sem paixões, onde a única forma de causar mobilização na população seria através do medo.

O medo descrito por Zizek (2015), por sua vez, é representado pelo medo do outro, dos imigrantes, da criminalidade etc. Manifesta-se, portanto, na subjetivação de uma multidão paranoica onde, nas 
palavras do autor, "o Outro ${ }^{3}$ está muito bem, mas só na medida em que a sua presença não seja intrusiva, na medida em que esse outro não seja realmente Outro" (p. 46). Desse modo, o medo espalha-se no tecido social de tal forma que vivemos desconfiados uns dos outros, tornando a articulação e convivência comunitárias cada vez mais escassas, e o isolamento social mais frequente, além de ser constitutivo de subjetividades e responsável por inúmeros quadros psicopatológicos na atualidade.

\section{Violência, simbolização e transgeracionalidade}

Um aspecto das vivências de violências com que tomamos contato e que nos chamou bastante atenção foi a falta de reconhecimento do sofrimento advindo dessas situações - tanto pela vítima, como pela sociedade de maneira geral. Tivemos contato com crianças que muito cedo viveram diversas formas de violência, desde a privação de elementos básicos, como moradia, alimentação, escola, lazer etc., até a destituição do poder familiar em decorrência de situações mais extremas. Nesses casos, a

\footnotetext{
${ }^{3}$ Aqui entendido em sua dimensão simbólica, como lugar que não se identifica com o semelhante, com o idêntico. O Outro referese ao princípio da alteridade, assim como
}

falta de reconhecimento da dor subjetiva decorrente dessas vivências gerava ainda mais sofrimento, uma vez que, sem lugar de legitimação, era difícil inscrever tais eventos em uma cadeia simbólica de significações.

Segundo Eizirik (2006), a falta de simbolização de acontecimentos traumáticos pode ser um fator gerador de adoecimento psíquico, sendo o tratamento psicanalítico uma possibilidade de atuação na construção proposto por Lacan (2004). Já o outro diz respeito àquele do imaginário. 
da integração psíquica e uma via para a representação simbólica desses eventos. Além disso, o autor destaca que essas dificuldades no processo de simbolização são frequentemente transmitidas através de gerações, podendo manifestar-se novamente em gerações futuras.

Benghozi (2000) mostra que a transmissão de conteúdos psíquicos se dá de uma geração para outra de maneira não linear e diferencia tais transmissões entre intergeracionais e transgeracionais. No primeiro caso, trata-se da transmissão de conteúdos psíquicos de uma geração para outra e, nesse trajeto, há elaboração de tais conteúdos pelos herdeiros que, por sua vez, os transmitem para uma terceira geração. Já no segundo caso, essa transmissão se dá de maneira não metabolizada e, desse modo, aquilo que diz respeito ao inominável é transmitido sem elaborações e simbolizações, gerando repetição entre as gerações. A transgeracionalidade se caracteriza, dessa forma, pela transmissão geracional de uma herança psíquica que é revivida por um indivíduo na atualidade, mas tem suas raízes em modos de funcionamento psíquico precedentes ao seu próprio nascimento. Esse fenômeno refere-se a conteúdos mentais não integrados, resultantes de vivências traumáticas que foram dissociadas e não simbolizadas através de palavras (Silva, 2005).

Há ainda que se considerar a abrangência na constituição das subjetividades coletivas quando nos referimos à produção e reprodução da violência. Nesse sentido, Souza (2015) nos aponta que, quando o Estado de Direito - que deveria ser capaz de sustentar um pacto social em que os interesses coletivos fossem prioritários em relação aos individuais - se perverte, ou seja, quando, ao invés de controlar a violência, é o próprio Estado que a produz através de suas ações ou pelo fracasso de tais ações, "a ideia de impunidade espalha-se pelo tecido social que infiltra o terreno das consciências individuais, generalizando-se numa descrença absoluta no poder do Direito e da Ética" (Souza, 2015, p. 89).

Birman (1994) afirma que as manifestações da violência na atualidade pressupõem o não reconhecimento da 
alteridade do outro, sendo este encarado como objeto de predação e gozo. É, no entanto, na possibilidade de representação simbólica que está a capacidade de se contrapor à necessidade de descarga direta das forças pulsionais agressivas, e nessa contraposição se daria a abertura para que o sujeito se constitua não como um projeto acabado, enrijecido e determinado por forças brutas, mas como um vir-à-ser.

Souza (2015) também nos mostra que é preciso que pensemos com base em análises e estratégias que articulem não só a dimensão macropolítica da violência, mas também a sua perspectiva micropolítica - como os processos de simbolização, desejos etc. -, uma vez que para trabalhar com essa temática não basta apenas considerar as

\section{Metodologia}

O presente artigo trata de um relato de experiência de uma residente multiprofissional em saúde mental e representações conscientes. Desse modo, entendemos a intervenção com crianças e suas famílias - quando a transmissão do traumático não simbolizado se manifesta e reatualiza de extrema importância, sendo a psicanálise uma relevante ferramenta clínica por nos fornecer uma visão profunda e crítica da cultura e da saúde mental.

A seguir, relataremos experiências com atendimento de crianças vítimas de violências que ocorreram durante os dois anos de residência, exemplificando, assim, as manifestações macro e micropolíticas desse fenômeno, bem como possíveis formas de intervenção no âmbito do tratamento e prevenção de adoecimentos psíquicos decorrentes de situações de exposição à violência.

saúde coletiva e seus orientadores no respectivo programa. Buscaremos realizar articulações teórico-práticas 
entre as experiências vividas durante os dois anos de atuação em dois equipamentos de saúde (CAPS infantojuvenil e UBS) situados em um município paulista, cujo histórico de lutas populares e participações da Universidade e do poder executivo municipal foi responsável pelo pioneirismo na implementação de políticas de saúde e estratégias de atenção à saúde que são referências nacionais até os dias atuais. Assim, o município possui hoje uma Rede de Atenção Psicossocial na atenção com alta densidade e heterogeneidade de serviços.

O referido Programa de Residência, inserido nesse contexto municipal, tem como objetivo promover a formação de profissionais de saúde orientados pelos pressupostos éticos e políticos do Sistema Único de Saúde e da Reforma Psiquiátrica Brasileira. Trata-se de uma estratégia de educação que visa contribuir para a construção e transformação das realidades sociais, ao mesmo tempo que pretende desenvolver uma práxis em saúde baseada na articulação entre os conhecimentos e práticas produzidos no cotidiano dos serviços de saúde e o conhecimento acadêmico. Tais articulações são feitas através da mediação com os supervisores e professores durante as supervisões grupais, individuais, dos seminários clínicos e das aulas (Onocko- Campos; Emerich e Ricci, 2019).

Desse modo, os residentes fazem o movimento de levar os casos com que tomam contato no cotidiano dos serviços para a universidade, onde as discussões se baseiam em referenciais teóricos de diversos núcleos de formação, além de privilegiar conteúdos da psicanálise, sendo esta uma disciplina que orienta as análises e posicionamentos éticos dos residentes (Onocko- Campos; Emerich e Ricci, 2019). Nossa experiência também se encontra inserida numa conjuntura municipal com complexa rede de serviços de saúde e forte tradição do conselho de saúde, que nos deram possibilidades de atuação a partir dos princípios da clínica ampliada, abrangendo ações de campo e núcleo nos serviços de saúde. (Campos, 2000). Assim, a construção dos relatos que seguem parte desse contexto, e foram construídos durante os encontros supervisionados, seminários clínicos e 
em conjunto com os pares dos serviços onde os estágios foram realizados.

Para Oury (1991), uma das consequências do processo formativo é a transformação de extratos da personalidade daquele que se encontra em formação. Assim, dentre os diversos casos e experiências com que tomamos contato durante esse período, selecionamos dois deles que tiveram impactos para os serviços de saúde e foram responsáveis por transformações de diversas ordens na residente multiprofissional em questão.

As duas experiências relatadas a seguir constituem-se, respectivamente, de um grupo de contação de histórias infantis ocorrido em um bairro periférico e vinculado a UBS - e um estudo de caso de um adolescente com quem tomamos contato durante o estágio no CAPS infanto-juvenil. Buscamos preservar a identidade dos sujeitos envolvidos, de modo que nomes foram alterados, bem como informações específicas dos casos foram ocultadas.

A experiência do caso relatado ocorreu durante um ano e foi acompanhada e supervisionada por meio de seminário clínico, para o qual a residente escreveu o estudo de caso com base em referenciais teóricos psicanalíticos (Nasio, 2001; Viganò, 1999), além de apresentá-lo para supervisores e residentes, e de ser construído em conjunto com a equipe multiprofissional do CAPS. Também foram realizadas supervisões individuais e grupais do caso, que contribuíram para a sua construção.

A experiência do grupo de contação de histórias infantis, por sua vez, também teve duração de um ano, com frequência semanal. Ele ocorria na rua em que as crianças moravam, onde estendíamos uma lona debaixo de uma árvore e participavam do grupo as crianças que tivessem interesse, de modo que os encontros eram abertos a todos, sendo possível a participação de novas crianças a cada encontro. Ao final do ano, cerca de vinte e cinco crianças passaram pelo grupo. Dentre estas, dez participaram do começo ao final do ano. Tal experiência foi orientada por meio de supervisões individuais e grupais, nas quais textos de autores como Pichon-Rivière (1983/2000), Kaës (2011), Castanho 
(2018), além de outras contribuições da psicanálise, orientaram nossas ações e interpretações, dando sustentação para

a formação e continuidade do grupo.

\section{Relatos de experiência}

\section{Grupo de contação de histórias infantis}

Quando iniciamos o estágio no centro de saúde, uma das agentes de saúde - que chamaremos aqui de R. - nos falava bastante sobre o território de sua abrangência, que era próximo da linha do trem, onde crianças morriam brincando, sem que os pais as vissem. Um território fora do mapa, composto por aquilo que muitos chamavam de invasão, mas que, entendendo a moradia como direito social fundamental previsto na emenda constitucional $n^{\circ} 26$, de 14 de fevereiro de 2000, nomeamos como ocupação. Tratase de uma tentativa dessa população de fazer valer seus direitos, uma vez que o próprio Estado, que deveria garantir a efetiva e ampla implementação de políticas de moradia, fracassa em suas ações.
Começamos a ir ao território semanalmente e, passadas algumas semanas conversando com os moradores, percebemos uma preocupação com as crianças, tanto em relação às questões escolares - muitas não eram alfabetizadas, apesar de estarem inseridas na escola - quanto em relação ao lazer, que era escasso. Sugerimos formar um grupo de crianças no território e os moradores apoiaram, iniciando, assim, nossos atendimentos.

A princípio colocamos uma caixa de som com algumas músicas para chamar atenção das crianças, começamos a encher algumas bexigas e estendemos uma lona, doada por uma das moradoras, debaixo de uma árvore para nos sentar. Aos poucos as crianças foram 
se aproximando e o grupo foi se formando. Sentadas no chão de barro debaixo da árvore com as crianças, por quase duas horas, nós saíamos de lá cobertas de terra em tom de cor avermelhado por todo o corpo, assim como a maior parte das famílias que viviam na região. Ao chegar ao centro de saúde, percebíamos nossas pegadas marrom-avermelhadas pelo chão branco daquele ambiente asséptico, fato que nos deu a primeira pista da marca da exclusão que as pessoas que acabávamos de encontrar viviam cotidianamente.

Levando em conta a necessidade de conhecer melhor a história de vida dessas crianças, propusemos levar histórias infantis, para que, a partir do lúdico e de uma possível identificação com os personagens fictícios, pudéssemos falar também sobre eles, seus sentimentos e suas vivências. Com o tempo, as crianças foram levando livros que gostariam de ler para o grupo. Certa vez, L. chegou com a história de João e Maria e, quando iniciamos o conto, diversas crianças se identificaram com os personagens principais, passando a relatar sobre castigos que já haviam sofrido. Cenas de violência foram aparecendo cada vez mais e no grupo procurávamos dar lugar de fala e reconhecimento da dor vivida por eles.

Temas como a morte, o luto e a tristeza também apareceram quando lemos o livro Sentimentos (Jones e Walden, 2019). Nesse dia, eles falaram sobre seus próprios sentimentos. D. falou sobre a morte do irmão no trilho do trem e sobre a tristeza que ele e sua família sentem até hoje. N. também falou sobre a morte da avó e do tio e J. disse da falta que o pai que está preso faz e como isso a deixa triste. A princípio, as crianças pareciam estar mais preocupadas em falar sobre seus sentimentos e não prestavam muita atenção no que os outros diziam, mas com o tempo notamos haver uma empatia entre os participantes, que passaram a escutar e a se identificar com as falas uns dos outros.

Notamos que faltava a alguns integrantes do grupo aquilo que Bion (1966 citado por Bleichmar, 2010) chama de função alfa, responsável pelo processo de simbolização. Nesse sentido, consideramos que faltava a esses participantes o olhar significativo de um 
adulto, de nomeação e interpretação das vivências de violência presentes em suas histórias de vida, com o intuito de dar lugar à representação simbólica que, de outra maneira, muitos colocavam em ato através de sintomas, como agressividade, choro frequente sem causa aparente, hiperatividade etc., que apareceram nos encontros que tivemos.

Presenciamos uma cena que nos parece ilustrar bem o quanto o reconhecimento de um sofrimento e a sua nomeação pode ser terapêutico. $S$. chegou para o grupo muito quieta, não quis envolver-se em nenhuma atividade e quando questionada sobre como estava se sentindo e se podíamos ajudá-la, ela não quis conversa. Em certa altura, ela passou a desenhar, sem conversar com os demais, e ainda muito quieta. Aproximamo-nos para ver seu desenho, que era de um dia chuvoso, e dissemos a ela: "Você resolveu desenhar um dia de chuva, apesar do dia hoje estar tão ensolarado. Será que o dia está chuvoso aí dentro de você?" S. começou a chorar copiosamente e disse que seu cachorro havia morrido por envenenamento e que sua mãe o colocou dentro de um saco de lixo, jogando-o fora. Conversamos sobre a necessidade que ela tinha de enterrar o cachorro, o quanto isso significava para ela. Ela disse que estava se sentindo muito triste e que não tinha tido ninguém para conversar até então. Falamos sobre o quanto é triste quando perdemos algo que amamos e pudemos legitimar sua dor. Depois dessa conversa, S. parecia mais aliviada e voltou a rir e brincar com as outras crianças, como nos encontros anteriores.

A partir dessa experiência, pudemos notar que $\mathrm{o}$ atendimento em grupo favoreceu que as crianças colocassem em cena o exercício da escuta mútua e da palavra dirigida a um Outro, aumentando, dessa forma, como nos aponta Souza (2005), a capacidade de identificação dos sujeitos entre si, de tolerância das diferenças e de elaboração simbólica de experiências traumáticas

\section{Estudos de caso}


Quando o estágio no CAPS infanto-juvenil foi iniciado, conheci T., um adolescente negro de 15 anos. Havia sido inserido no serviço há cerca de seis anos. Segundo a equipe, isso tinha acontecido logo após o processo de destituição da guarda familiar. Era comum que no CAPS T. quebrasse objetos propositalmente, agredisse e ameaçasse agredir pessoas dentro do serviço. As cenas violentas, fossem elas produzidas pelo próprio T., pela equipe ou por ambos, pareciam naturalizadas, de forma que dificilmente se discutia com ele ou com a equipe o que havia acontecido.

No espaço da convivência no CAPS, T. começou a se aproximar de mim, me procurando com bastante frequência para conversar. Diante da grande demanda por essas conversas, propus que esses atendimentos fossem realizados em uma sala para que ele tivesse um tempo e espaço específicos para tratar de suas questões. Logo no primeiro atendimento em sala já fizemos alguns acordos, como horário, local e frequência dos atendimentos. Ele concordou com os termos colocados e disse querer que eu fosse sua amiga, fazendo logo a proposta e finalizando: "Fala logo se você quer ou não!". Diante de seu convite, o questionei sobre o que significava uma amizade para ele. No momento ele não soube responder, porém, tal questão foi trazida por ele novamente em outros atendimentos.

T. dizia de um medo de si mesmo, de sua origem e daquilo que acreditava ser capaz de fazer. Desde muito cedo ele saiu de seu lar (aos seis anos) e, durante sua passagem pelas instituições de acolhimento, foi ouvindo histórias muito violentas sobre seus pais, que não necessariamente eram verdadeiras, mas que eram muito fortes e difíceis de serem elaboradas para uma criança, cuja personalidade ainda não estava totalmente integrada. Além dessas histórias, também podemos considerar que a vivência em abrigos, circunscrita por inúmeras violências, não fornecia a ele um ambiente estável e pessoal, onde ele pudesse vivenciar experiências de amor, força e tolerância, que suportasse com êxito todos os testes que ele, por ventura, fizesse ao ambiente. Assim, ele se via privado de um ambiente seguro em que pudesse aprender a tolerar e 
dominar seus impulsos, sendo impedido, portanto, de ser livre e irresponsável, tornando-se angustiado e inquieto e passando a ter medo de seus próprios pensamentos e imaginação (Winnicott, 1964).

Após esse começo, T. passou a atacar os espaços da instituição e da psicoterapia. Por semanas seguidas, durante alguns meses, quando era chamado para entrar na sala, ele gritava dizendo que não entraria. Eu respondia que continuaria esperando por ele no local e durante o tempo acordados, mesmo que ele não fosse. Nesses dias, depois de algum tempo, ele aparecia na sala e o atendimento era iniciado. Porém, depois dessa cena se repetir algumas vezes, ele começou a quebrar objetos, gritar e ameaçava me agredir toda vez que era chamado para entrar na sala. Mesmo assim, minha postura continuou a mesma: ia para dentro da sala e lá permanecia, esperando-o. Ao observar que nada disso adiantava e que mesmo assim eu continuava ali até o fim do tempo combinado com ele, em algum momento, sentava-se e conseguia colocar em palavras o que estava sentindo.

T. também relatava não conseguir controlar sua agressividade, apresentando esse elemento como uma queixa em diversos momentos, muito embora se orgulhasse, em certa medida, por saber se defender sozinho. Precisamos reconhecer que sua vida foi, desde muito cedo, determinada pelo poder judiciário, que agiu por diversas vezes contra a sua própria vontade, escutando mais as instituições e os pareceres de especialistas sobre o caso do que a ele próprio. Assim, ele apresentava uma raiva muito clara e dirigida às instituições do judiciário que, com o discurso da proteção, tanto o violentaram.

Nesse sentido, entendemos que $T$. carregava consigo um sentimento de oposição ao poder que se manifestava de forma evidente nas instituições que percorreu até hoje. Segundo Basaglia (1968), esse sentimento desperta forças pessoais de reação e de conflito, forças estas que podem ser manifestadas através da agressividade. Segundo o autor, esse pode ser um ponto com forte 
potencial para a sua reabilitação, sendo necessário que o tratamento terapêutico não negue as violências vividas pelos sujeitos, mas, pelo contrário, conserve o "laço do doente mental com sua história, que é sempre uma história de abuso e de violência, denunciando claramente, e de modo permanente, a fonte da violência e do abuso" (p. 131). Foi, portanto, interpretando a relevância da agressividade como fonte de resistência e produção de saúde - e não apenas como sintoma a ser trabalhado - que pude sustentar a escuta e o espaço terapêutico de T.

Buscando entender as nuances do fenômeno da agressividade em T., recorremos a diversos referenciais teóricos que pudessem orientar nossa prática. Assim, também consideramos o que Winnicott (1964) nos esclarece sobre atos antissociais extremos, os quais podem ser interpretados como uma necessidade da criança ou do adolescente em encontrar um pai rigoroso, que pode também ser carinhoso, mas que consegue, ao mesmo tempo, ser severo e forte. Quando essa figura paterna está em evidência, é possível recuperar os impulsos amorosos primitivos, o sentimento de culpa e o desejo de se corrigir. Caso isso não seja possível, a criança ou o adolescente pode tornar-se cada vez mais inibido no amor, sendo incapaz de sentir a realidade das coisas, exceto a realidade da violência.

Nesse sentido, entendemos que $T$. ainda buscava essa figura paterna, muito embora não possamos dizer que estivesse totalmente ausente em sua vida e que ele tivesse impulsos amorosos extremamente inibidos, uma vez que durante o tempo em que $\mathrm{o}$ atendi, demandas de amor foram claramente dirigidas a mim, sendo possível perceber uma busca pela figura materna. Assim, à pergunta do começo dos atendimentos sobre o quê, para ele, significava amizade, ele trouxe a resposta em outras sessões, retomando que gostaria que eu fosse sua amiga e que ser amiga era ser aquela que dá conselhos, diz para ele quando tem que parar e também é aquela que cuida, dá carinho e amor. Logo após ter dito isso, ele associou que essas também são as funções dos pais. 
Em outros momentos, T. se comparou a Lúcifer ${ }^{4}$, dizendo que eu era "igualzinha a Linda", personagem da terapeuta de Lúcifer, e ressaltou, ao final de nossos atendimentos, que a cena que mais gostou da série foi quando Linda descobriu que Lúcifer era o diabo, mas mesmo assim ela o aceitou, sendo possível, a partir dessa relação, segundo o que ele disse, "que Lúcifer pudesse amar verdadeiramente e se relacionar com outras mulheres". Assim, entendemos que ter sobrevivido aos ataques que $T$. fez ao espaço da psicoterapia - dando lugar para que não apenas forças brutas se manifestassem, mas ajudando-o no processo de simbolização de eventos traumáticos - fez com que ele passasse a confiar nessa relação e se sentisse mais livre para estabelecer outras.

Após um ano do encerramento dos atendimentos de T., tivemos notícias de que ele conseguiu manter a frequência escolar (algo que era muito almejado por ele), apesar de alguns episódios de agressão ainda ocorrerem, e de que também não necessitou mais da medicação neuroplética injetável que tomava para controlar impulsos agressivos. Hoje ele não frequenta mais o CAPS, mas o serviço ainda mantém contato com o abrigo, acompanhando o caso a distância.

\section{Por trás das cortinas da proteção: violência institucional}

A violência na vida dos sujeitos com os quais tomamos contato manifesta-se

\footnotetext{
${ }^{4}$ Em referência a série de televisão americana criada por Tom Kapinos (2016).
}

cotidianamente e espalha-se por muitos âmbitos de suas vidas, sendo 
reproduzida também dentro dos equipamentos de saúde e assistência que pretendem cuidar dessa população.

Desse modo, foi possível notar que faltavam espaços para a construção de decisões democráticas nos serviços de acolhimento institucional às crianças e adolescentes. Os horários das atividades e deliberações sobre regras, compras e até mesmo sobre o lazer eram decididos de forma vertical e comunicados àqueles que mais importam, que são as crianças e adolescentes moradores. Além disso, a distância de uma das instituições com que tivemos contato se colocava como um grande impedimento de convívio, não só familiar, mas comunitário também.

Segundo Goffman (1961), as tendências de "fechamento" da instituição, representadas pela barreira física, por suas regras rígidas em relação ao convívio com o restante da sociedade, e a divisão nítida entre equipe dirigente e aqueles que estão institucionalizados são algumas características das chamadas instituições totais. A vida nessas instituições pode gerar sentimentos de inferioridade, fraqueza e culpa. Além disso, a falta de controle sobre as decisões que são tomadas e que afetam diretamente suas vidas retira dessas crianças e adolescentes parte importante de sua autonomia, podendo se constituir como uma forma de mortificação do eu. A conjugação de tais fatores contribui para que a instituição seja vista como lugar sem saída, onde aqueles que ali se encontram sejam vistos como fracassados, incapazes e perigosos, reforçando assim o estigma social vivenciado por esses sujeitos, além de contribuir para o desenvolvimento de intenso sofrimento psíquico (Soares, 2012).

Nesse sentido, a passagem dos adolescentes pelas diversas instituições de acolhimento reflete a fragilidade dos mecanismos de proteção ao longo de suas vidas. Essa fragilidade, por sua vez, não se encontra somente no âmbito familiar, mas também, e sobretudo, nas instituições e políticas públicas que se propõem a cuidar desses sujeitos para que estejam protegidos dos contextos de privação e violência, mas fracassam em suas ações (Soares, 2012). 
Também pudemos observar que no CAPSij os profissionais apresentaram dificuldades repetidas em acolher as demandas agressivas de algumas crianças e adolescentes institucionalizados. É preciso reconhecer que esse é um ponto difícil, mas necessário de ser suportado por esse serviço. Assim, nos momentos de agressividade desses usuários, o acolhimento se deu absorvendo a demanda trazida por eles e produzindo uma resposta agressiva por parte do próprio serviço de saúde mental. Nesse sentido, é preciso nos questionarmos: estaríamos, desse modo, reproduzindo a violência histórica vivida por esses sujeitos quando agimos assim?

Basaglia (1968), ao nos descrever a experiência com a comunidade terapêutica como alternativa aos hospícios, nos aponta a necessidade essencial de que, mesmo a partir de movimentos que visem às reformas do modelo manicomial, é preciso que não tenhamos os serviços substitutivos como uma meta final, mas como uma fase transitória possível de evolução. É, pois, com o reconhecimento e discussão constantes das contradições da realidade posta e da diferença de forças de poder que se torna possível uma ação terapêutica. Assim, qualquer ação que venhamos desenvolver no trato com os usuários dos serviços de saúde mental continuará oscilando "entre a aceitação passiva e o rechaço da violência sobre a qual se funda nosso sistema sóciopolítico." (p. 113).

Para além dos serviços de acolhimento institucional e do Centro de Atenção Psicossocial, outras faces da violência também puderam ser percebidas na atenção básica, não sendo raras as situações em que profissionais fizeram julgamento moral de usuários ou de famílias inteiras, devido às precárias condições de vida às quais estavam submetidos, de modo que algumas crianças atendidas no grupo de contação de histórias, por exemplo, eram tidas como "encardidinhas" e suas famílias consideradas "negligentes". Diante dessas questões, podemos dizer que tais usuários vão sendo desqualificados socialmente, de forma que a culpa individual pela condição de pobreza e o juízo depreciativo sobre si mesmo é 
internalizado, manifestando-se muito frequentemente pelo isolamento social e sentimento de vergonha de si.

\section{Considerações finais}

Este artigo parte de experiências práticas que nos instigaram a debater as possibilidades de intervenções macro e micropolíticas sobre os determinantes da violência. Expusemos que o silêncio diante dessa violência é devastador e que o ato clínico e político de resgatar a memória e ajudar a produzir narrativas sobre esses acontecimentos pode contribuir no aspecto micropolítico desse fenômeno. Também buscamos discutir os determinantes sociais na produção e reprodução da violência.

Chamamos a atenção para os processos de estigmatização e para a naturalização da condição social de marginalizado, mecanismos que contribuem para reforçar, expandir e reproduzir a violência e a exclusão. O estigma, que pode ser entendido como o processo de qualificação e desqualificação do indivíduo dentro da lógica da exclusão (Goffman, 1963), atua não só para a manutenção da ordem dominante e das desigualdades sociais, mas também faz com que os direitos sejam transformados em favores e as políticas públicas encaradas como assistencialismo, tanto para aqueles que delas usufruem diretamente, como pelos próprios profissionais, que muitas vezes atuam como se estivessem fazendo caridade. Desse modo, é preciso que tenhamos em vista a necessidade de desnaturalizar as questões sociais como um fator importante para a instrumentalização de práticas efetivas no trato com os sujeitos vítimas de violência e marginalização (Wanderley, 2001).

Este trabalho também se empenhou na defesa de que ações pontuais de alguns serviços ou dalguns profissionais podem 
ter alguma relevância, mas "as causas estruturais que determinam as condições de pobreza dos sujeitos não são passíveis de serem enfrentadas por meio dessas ações" (Fávero, 2007, p. 191). Assim, o enfrentamento dessas questões depende de ações micropolíticas integradas à luta popular, medidas sociais e políticas públicas amplas. Caso contrário, corremos o risco de cair na lógica de caridade com que 0 assistencialismo se propõe a agir

\section{Referências}

Basaglia, F. (1968). A instituição negada: relato de um hospital psiquiátrico. Trad. Heloísa Jahn. Rio de Janeiro: Edições Graal.

Benghozi, P. (2001). Traumatismos precoces da criança e transmissão genealógica em situação de crises e catástrofes humanitárias: desemalhar e reemalhar continentes genealógicos familiares e comunitários. In CORREA, O. (Org.). Os avatares da transmissão psíquica geracional. São Paulo: Escuta, p.89100.

Birman, J. (1994). Psicanálise, ciência e cultura. Rio de Janeiro: Jorge Zahar. Bleichmar, S. (2010). Psicoanálisis extramuros: Puesta a prueba frente a lo traumático. Buenos Aires: Editorial Entreideas.

Campos, G.W.S. (2007). Reforma Política e Sanitária: a sustentabilidade do SUS em questão. Ciência \& Saúde Coletiva; mar./abr.,12(2), 301-306.

Campos, G.W.S. (2000). Saúde Pública e Saúde Coletiva: campo e núcleo de Saberes e práticas. Ciência e Saúde Coletiva, 5(2), 219-230 
Coimbra, C. (2001). Operação Rio: o mito das classes perigosas. Rio de Janeiro: Oficina do Autor, Intertexto.

Coimbra, C. (2000). Psicologia, Direitos Humanos e Neoliberalismo. Revista Psicologia Política, 1(1), 139-148.

Correa, O. B. R. (Org.). Eclosão dos vínculos genealógicos e transmissão psíquica. In: . Os avatares da transmissão psíquica geracional. São Paulo: Escuta, 2000b. p. 61-71.

Eizirick, C. L. (2006). Sobre a prevenção da transmissão transgeracional da guerra, do ódio e da violência: uma perspectiva psicanalítica. Psicanalítica, 7(1). Euzébios Filho, A. (2011). Psicologia e desigualdade social: um estudo sobre a consciência política de beneficiários de programas de transferência de renda. Curitiba: Juruá.

Fávero, E. T. (2007). Questão social e perda do poder familiar. São Paulo, SP: Veras Editora.

Figueiredo, A. N. (2007). A construção do caso clínico: uma contribuição da psicanálise à psicopatologia e à saúde mental. Revista Latinoamericana de Psicopatologia Fundamental, 7(1), 75-86.

Goffman, E. (1963/2012). Estigma: notas sobre a manipulação da identidade deteriorada. Trad. Márcia Bandeira de Mello Leite Nunes, $4^{a}$ ed. Rio de Janeiro, RJ: LTC.

Goffman, E. (1961/2013). Manicômios, prisões e conventos. Trad. Dante Moreira Leite. 8. ed, São Paulo, SP: Perspectiva.

Guareschi, P. (2001). Pressupostos psicossociais da exclusão: competitividade e culpabilização. In B. Sawaia. (Org.). As artimanhas da exclusão: análise psicossocial e ética da desigualdade social. Petrópolis: Vozes, p.141-156. 
Hofling, E. M. (2001). Estado e políticas (públicas) sociais. Cadernos Cedes, 55, 30-41.

Jones, R. \& Walden, L. (2019). Sentimentos. São Paulo: Ciranda Cultural.

Kaës, R. (2011). Um singular plural: A psicanálise à prova do grupo. Trad. Luiz Paulo Rouanet. São Paulo: Edições Loyola.

Leite, V. E. P. \& Euzébios Filho (2018). Processos de inclusão/exclusão social: como os usuários de crack enxergam suas trajetórias de vida. Revista de Psicologia, Fortaleza, v. 9, p. 107-116.

Lênin, V.I. (1918/2010). O estado e a revolução: o que ensina o marxismo sobre o Estado e o papel do proletariado na revolução. São Paulo: Expressão Popular.

Nasio, J. -D. (2001). O que é um caso? In Nasio, J. -D. (Org.). Os grandes casos de psicose. Trad. Vera Ribeiro. Rio de Janeiro: Jorge Zahar Editor.

Onocko-Campos, R., Emerich, B. F., \& Ricci, E. C. (2019). Residência Multiprofissional em Saúde Mental: suporte teórico para o percurso formativo. Interface - Comunicação, Saúde, Educação.

Oury, J. (1991). Itinerários de formação. Rev Prat., p. 42-50.

Pichon-Rivière (1983/2000). O Processo Grupal. São Paulo: Editora Martins Fontes.

Sawaia, B. (2001). As artimanhas da exclusão: análise psicossocial e ética da desigualdade social. Petrópolis, RJ: Editora Vozes.

Silva, M. C. P. (2005). O fenômeno transgeracional ilustrado em três momentos da vida - na infância precoce, na adolescência e na vida adulta. In Barone, L. M.C; Arruda, A. P de B; Augusto, J. P.; F.; Saddi L. \& Freitas, S. R. M. S. (Orgs.). A psicanálise e a clínica extensa - III Encontro Psicanalítico da Teoria dos Campos. Escrito. São Paulo: Casa do Psicólogo, p. 341-370. 
Soares, S. M. G. de M. (2012). Família - Abrigo - Rua: Construção de significados dos adolescentes nas passagens por contextos de desenvolvimento. Tese de Mestrado, Programa de Pós-Graduação em Psicologia da Universidade Federal de Pernambuco.

Souza, M. L. R (2005). Violência. São Paulo: Casa do Psicólogo.

Viganò, C. (1999). A construção do caso clínico em saúde mental. Curinga,13. Belo Horizonte: EBP-MG, p.50-59.

Winnicott, D. W. (1964). A criança e o seu mundo. $6^{\mathrm{a}}$ ed. Rio de Janeiro: LTC. Zizek, Slavoj. (2014). Violência: seis reflexões laterais. Trad. Miguel Serras Pereira. São Paulo: Boitempo.

Recebido em: 21/08/2020 Aprovado em: $15 / 12 / 2020$ 